\title{
A descentralização pedagógica em uma ação educomunicativa guiada pela sequência Fedathi
}

Marcus Henrique Linhares Ponte Filho

Doutor e mestre em Educação pelo Programa de Pós Graduação em Educação da Faculdade de Educação (FACED/UFC). Professor adjunto na Universidade Federal do Cariri (UFCA).

E-mail: marcus.henrique@ufca.edu.br

Hermínio Borges Neto

Professor titular da Universidade Federal do Ceará (UFC), lotado no Laboratório de Pesquisa Multimeios da Faculdade de Educação da UFC

E-mail: herminio@multimeios.ufc.br

Resumo: Este artigo analisa o que docentes de uma escola municipal de (CE) pensam a respeito da "descentralização pedagógica" a partir de suas próprias rotinas profissionais. O ensaio é fruto de uma atividade de extensão realizada no período de agosto de 2019 a outubro de 2019 que ofereceu uma formação pedagógica educomunicativa, tendo como suporte metodológico a sequência Fedathi, uma metodologia de ensino que busca estimular o raciocínio científico nas práticas pedagógicas por meio do aprimoramento da ação docente. Pôde-se constatar que os educadores interpretaram a ideia de democratizar a prática docente como algo quase inaplicável, e que o conceito de "descentralização pedagógica" era quase sempre atrelado à perda de autoridade em sala de aula.

Palavras-chave: educomunicação; descentralização pedagógica; professores; sequência Fedathi.
Abstract: This article analyzes what teachers from a school of the public network of Fortaleza, state of Ceará, think about "pedagogical decentralization", based on their own professional routines. The essay is the result of an extension activity conducted from August 2019 to October 2019 that offered a pedagogic educative communication training, using the Fedathi Sequence as methodological support (a teaching methodology that seeks to stimulate scientific reasoning in pedagogical practices by improving teaching action). It could be seen that educators interpreted the idea of democratizing teaching practice as something almost inapplicable, and that the concept of "pedagogical decentralization" was almost always linked to the loss of authority in the classroom.

Keywords: educommunication; pedagogical decentralization; teachers; Fedathi sequence. 


\section{INTRODUÇÃO}

Um dos principais objetivos defendidos no campo da educomunicação é o de enriquecer a comunicação mantida entre os sujeitos em situações educativas. Para isso, este campo do conhecimento propõe o uso de iniciativas pedagógicas que levem em consideração a descentralização da ação docente, considerando a imagem do professor não como detentor e transmissor de conhecimentos, mas como mediador de uma aprendizagem pautada numa construção coletiva do saber através da criação de ecossistemas comunicativos.

O acesso democrático ao conhecimento citado no paradigma educomunicativo passa necessariamente pelo diálogo entre os envolvidos no processo de ensino-aprendizagem: professores e alunos. Estes precisam analisar juntos os conteúdos abordados em sala de aula como forma de construírem interpretações a respeito do conteúdo'.

Este artigo apresenta os resultados de uma ação extensionista realizada em uma escola municipal de Fortaleza (CE) no segundo semestre de 2019, em que foi analisada a forma como os participantes do projeto interpretaram o conceito de "descentralização pedagógica". Inicialmente, apresenta-se de forma sucinta alguns conceitos pedagógicos da sequência Fedathi, metodologia de ensino que orientou todo o projeto de extensão. Em seguida é descrita a ação de extensão, assim como seus pormenores, procurando mostrar ao leitor como a sequência Fedathi foi aplicada no decorrer das atividades realizadas com os participantes do projeto. Finalmente, são analisados alguns posicionamentos dos participantes da ação a respeito da "descentralização pedagógica" e o receio que essa ideia educomunicativa causava entre os professores da instituição.

\section{SEQUÊNCIA FEDATHI: QUE MÉTODO DE ENSINO É ESSE?}

A sequência Fedathi é uma metodologia de pesquisa e ensino idealizada pelo professor Hermínio Borges $\mathrm{Neto}^{2}$, docente titular da Universidade Federal do Ceará (UFC) que trabalha no Departamento de Estudos Especializados da Faculdade de Educação da UFC. Esta metodologia é focada no trabalho do professor, em suas atitudes, em seu comportamento e em sua postura. Inicialmente aplicada no ensino de matemática por conta da formação de seu idealizador, a sequência Fedathi teve aos poucos sua aplicabilidade ampliada e passou a ser adotada também como metodologia de pesquisa e ensino em diversas outras áreas, como física, desenvolvimento de jogos eletrônicos, ensino à distância e educação - incluindo formação de professores. Assim, seu viés científico e construtivista rapidamente ganhou popularidade entre os docentes que passaram a utilizar o método em suas aulas.

Segundo Souza ${ }^{3}$, a sequência Fedathi propõe uma nova forma de aprendizagem aos alunos, baseada no levantamento de hipóteses para explicar conceitos 
a partir do método científico; ou seja: é o método científico aplicado ao ensino. A sequência Fedathi propõe que ao se deparar com um problema, o aluno aborde os dados da questão, experimente vários caminhos que possam levar a uma solução (no sentido de uma resposta ao problema), "analise possíveis erros, busque conhecimentos para constituir sua solução, teste os resultados para saber se errou e onde errou, corrija-se e monte um modelo"4.

Borges Neto ${ }^{5}$ afirma que o método tradicional de ensino pressupõe apenas duas etapas: a transmissão de conceitos por parte do professor e a absorção desses conceitos por parte dos alunos. Dessa forma, a sequência Fedathi propõe o ato pedagógico em quatro etapas interdependentes: a tomada de posição, quando os estudantes são inicialmente apresentados a alguma questão específica que irá requerer sua reflexão; a maturação, quando os discentes irão aprofundar reflexões sobre a questão apresentada e elaborar hipóteses para uma resposta ao problema; a solução, etapa em que os estudantes, mediados ou não pelo professor, irão testar as hipóteses levantadas e comprovar sua veracidade através da troca de ideias; e a prova, etapa em que o professor, juntamente com os alunos, irá sintetizar as respostas dos alunos com o intuito de generalizar a solução encontrada de forma que ela seja aplicável em outras situações ${ }^{6}$.

Dessa forma, como o aluno é instigado a abordar o conhecimento de uma maneira diferente, a sequência Fedathi propõe ao professor uma reorientação de sua própria experiência docente, na qual ele passará a ser um mediador do conhecimento e não um transmissor de conteúdo, estimulando os estudantes a melhorar suas reflexões a partir da sugestão de novas situações-problema que coloquem em xeque suas próprias convicções. Dessa forma, entra em cena um importante conceito trabalhado na sequência Fedathi, que a aproxima consideravelmente da educomunicação: a chamada pedagogia mão no bolso, que propõe ao docente agir de forma que possibilite um protagonismo do estudante na abordagem dos problemas apresentados, dando ao discente a autonomia para construir suas próprias soluções e respostas sem se sentir necessariamente “dependente" do professor ou atrelado às suas ideias ${ }^{7}$, embora o processo de conhecimento seja mediado por ele.

Certos aspectos trabalhados no campo da educomunicação e alguns princípios abordados na sequência Fedathi enquanto metodologia de ensino chamam a atenção pelo enriquecimento da comunicação mantida no processo pedagógico. Esse diálogo científico entre a educomunicação e a sequência Fedathi facilitou a escolha desta metodologia usada no projeto, uma vez que fica nítida a aproximação conceitual de certos aspectos comuns aos dois campos, como o incentivo à construção do aprendizado por parte do discente e o respeito aos conhecimentos prévios demonstrados pelos alunos.

A etapa conhecida como maturação no método pedagógico proposto na sequência Fedathi propõe uma reorientação do papel do professor por meio de uma descentralização da experiência didática: o docente dá espaço aos alunos para refletirem, questionarem e cogitarem hipóteses para a solução de questões que lhe sejam apresentadas. Com o auxílio da chamada pedagogia mão no
4. Ibidem, p. 18.

5. BORGESNETO, Hermínio et al. (org.). Sequência Fedathi: uma proposta pedagógica para o ensino de ciências e matemática. Fortaleza: Edições UFC, 2013.

6. MENEZES, Daniel Brandão. Prova. In: BORGES NETO, Hermínio (org). Sequência Fedathi: fundamentos. Curitiba: CRV, 2018. p. 99-106.

7. SANTANA, Ana Carmen de Souza. Mão no bolso: postura, metodologia ou pedagogia? In: BORGES NETO, Hermínio (org). Sequência Fedathi: fundamentos. Curitiba: CRV, 2018. p. 15-22. 
bolso, outro conceito comumente trabalhado na sequência Fedathi, o professor passa a agir como um fomentador de dúvidas: um questionador que media a construção de uma aprendizagem baseada na experiência direta dos estudantes e na validação de suas suposições ${ }^{8}$. Essa autonomia, estimulada pelo professor, gera um enriquecimento na comunicação mantida no ambiente escolar: os estudantes passam a testar suas suposições e hipóteses e a questionar conceitos junto a seus professores, ampliando também a comunicação com os próprios colegas de turma na busca por soluções e reflexões sobre os conteúdos. Temos aqui a clássica construção do chamado "ecossistema comunicativo", conceito tão importante no campo da educomunicação e pautada no respeito mútuo e na manifestação de uma comunicação essencialmente democrática ${ }^{9}$.

Outro grande ponto de encontro entre a educomunicação e a sequência Fedathi no que tange ao aumento do protagonismo estudantil dá-se por meio do chamado contraexemplo: trata-se de um conceito fedathiano que propõe que o professor não responda afirmativamente e de forma direta questionamentos dos estudantes, mas forneça respostas através de novas perguntas que suscitem a reflexão na atividade. Dessa forma, o docente pode mediar a aprendizagem dos alunos por meio do estímulo à reflexão do estudante sobre as ações que tem realizado ${ }^{10}$, fazendo com que, na prática, o uso de contraexemplos busque gerar um enriquecimento da argumentação científica dos alunos, tornando os alunos sujeitos ativos dos processos educacionais e não apenas receptores de informações transmitidas de maneira unidirecional.

\section{O PROJETO DE EXTENSÃO E A APLICAÇÃO DA SEQUÊNCIA FEDATHI COMO SUA BASE METODOLÓGICA}

O trabalho de extensão que originou este trabalho seguiu uma lógica educomunicativa. Intitulado "Comunicação com Qualidade: uma proposta de aplicação da Educomunicação ao processo de ensino por meio da Sequência Fedathi”, o projeto propôs a professores de uma escola municipal de Fortaleza a discussão de temas caros ao campo da educomunicação e intensamente presentes em sua rotina profissional, como "poder em sala de aula", "produção autoral", "descentralização pedagógica" e "autonomia”.

Organizado em formato de curso de formação continuada, o projeto foi

8. SOUZA, Op. cit., p. 18.

9. SOARES, Ismar de Oliveira Educomunicação: o conceito, o profissional, a aplicação. São Paulo: Paulinas, 2011.

10. FERREIRA, Flávia de Carvalho. Contraexemplo. In: BORGES NETO, Hermínio (org). Sequência Fedathi: fundamentos. Curitiba: CRV, 2018. p. 49-54. coordenado pelos professores Marcus Henrique Linhares Ponte Filho, docente adjunto da Universidade Federal do Cariri, e Hermínio Borges Neto, docente titular da Universidade Federal do Ceará. A ação contou também com a participação voluntária de colaboradores que também pesquisam (e trabalham) com educomunicação, como a jornalista Sara Rebeca Aguiar de Carvalho e a pedagoga Cristina Mandau Ocuni Ca.

A ação extensionista foi realizada em sessões semanais com encontros realizados após o expediente letivo dos professores e em horário acordado previamente com os participantes. O projeto foi realizado entre os meses de 
agosto e outubro de 2019, e contou com a participação ativa de 11 docentes dos anos iniciais do Ensino Fundamental ( $1^{\circ}$ ao $5^{\circ}$ Ano), regularmente lotados na instituição visitada.

Foram realizados nove encontros semanais de formação pedagógica junto aos professores participantes, em que cada encontro teve duração aproximada de uma hora. A formação pedagógica foi guiada por temas que nortearam as discussões realizadas pelos participantes ao longo das sessões. O objetivo da ação de extensão não era simplesmente lecionar sobre educomunicação aos participantes do projeto; ao contrário, tinha a intenção de compreender a realidade dos professores a partir das experiências pedagógicas que eles poderiam apresentar ao longo dos encontros. Isso daria aos participantes a consciência de que o projeto se basearia em um momento de construção coletiva de conhecimento, e não simplesmente em uma situação de transmissão unilateral de saberes, o que fatalmente daria à ação o formato que as formações pedagógicas da atualidade geralmente já possuem: momentos pouco democráticos e comunicativamente pobres ${ }^{11}$. Por conta disso, houve a escolha de realizar os debates da ação extensionista através de temas geradores, porque objetivava-se dar ao projeto uma abordagem essencialmente freireana, pautada em reflexões de temas pertinentes à rotina profissional dos docentes, o que atrairia sua atenção a partir do momento em que suas próprias experiências de vida passariam a ser objeto de análise e valorização ${ }^{12}$.

Ao longo dos dois meses de realização da ação de extensão, temas como “descentralização pedagógica", "produção autoral”, "autoridade" e "segurança na internet" foram intensamente debatidos nos encontros realizados. As discussões realizadas tiveram o intuito de compreender o pensamento dos profissionais a respeito dos conceitos abordados na formação. Era mais importante saber como os participantes interpretavam os temas geradores que simplesmente ministrar esses conceitos de maneira teórica e expositiva, o que fatalmente tornaria a ação repetitiva, enfadonha e infrutífera; um reflexo do que os participantes provavelmente já têm em sua rotina profissional ${ }^{13}$.

Como o objetivo principal do projeto de extensão era compreender a interpretação dos participantes a respeito dos temas geradores abordados nas discussões, procurou-se dar total ênfase na reflexão dos próprios professores a respeito das experiências pedagógicas que narravam ao longo da formação. Por isso, foram usadas as quatro etapas da sequência Fedathi ao longo de todo o projeto: tomada de posição, maturação, solução e prova. Estas etapas foram aplicadas ao longo da ação de extensão da seguinte forma:

(1) Dias antes de cada encontro da formação, todos os professores eram convidados a registrar em vídeo (por celular) as atividades de sua aula em que considerassem estar tendo dificuldades para ministrar algum conteúdo específico. Essa era a etapa da tomada de posição dos participantes diante de um problema apresentado por eles mesmos a partir de sua própria rotina profissional. A produção do vídeo era completamente voluntária, e nenhum dos participantes era obrigado a fazê-lo;
11. KAPLÚN, Mario. Uma pedagogia da comunicação. In: APARICl, Roberto (org.). Educomunicação: para além do 2.0. São Paulo: Paulinas, 2014. p. 59-80.

12. FREIRE, Paulo. Pedagogia do oprimido. Rio de Janeiro: Paz e Terra, 2014.

13. LIBÂNEO, José Carlos. Didática. 2a. ed. São Paulo: Cortez, 2013. 
(2) Ao início de cada encontro da formação, os participantes eram convidados a assistir e debater os vídeos das aulas que eles mesmos registravam. Todos os vídeos registrados pelos professores eram compartilhados em um grupo privado do aplicativo WhatsApp, como forma de coletivizar os conteúdos produzidos e manter o anonimato dos envolvidos no projeto (especialmente os alunos);

(3) Após assistir aos vídeos, os participantes recebiam um tempo para iniciar uma reflexão coletiva em pequenos grupos. Essa reflexão sobre as dificuldades enfrentadas pelos companheiros de profissão seria feita a partir do tema gerador sugerido a cada encontro pelo coordenador do projeto (etapa de maturação);

(4) Após a discussão nos grupos, os professores compartilhavam suas conclusões a respeito do vídeo apresentado, tentando refletir sobre as dificuldades manifestadas pelo professor que havia produzido aquele vídeo em sua aula. Iniciava-se então um debate coletivo por meio do compartilhamento de experiências dos outros participantes (etapa de solução), atuando o coordenador da ação extensionista como mediador das discussões que seriam realizadas de forma educomunicativa por meio do uso de conceitos trabalhados na sequência Fedathi;

(5) Ao fim do debate coletivo, o coordenador da ação de extensão apontava questões sobre os posicionamentos apresentados pelos professores (etapa da prova) a partir dos pressupostos epistemológicos da educomunicação. Sugeria-se então aos participantes a produção de um novo vídeo para o encontro seguinte, apresentando-se assim o tema gerador a ser abordado na semana seguinte.

Todos os encontros da formação pedagógica foram registrados através de filmagem, e a autorização de utilização desses registros para fins acadêmicos foi dada pelos próprios docentes por meio do preenchimento de termo de consentimento. Para fins de análise, todos os nomes apresentados neste artigo são fictícios, e a identidade dos docentes foi mantida no mais absoluto sigilo.

\section{ENTRE A ADMIRAÇÃO E O RECEIO: O DISCURSO DOS PARTICIPANTES SOBRE O CONCEITO DE "DESCENTRALIZAÇÃO PEDAGÓGICA"}

De uma forma geral, pôde-se perceber que alguns dos participantes tinham dificuldade em admitir a aplicabilidade do conceito de "descentralização pedagógica” em sua rotina profissional, muitas vezes interpretando esse conceito como algo didaticamente "inaplicável" ou "perigoso" didaticamente. Para alguns dos participantes da formação, o ato de descentralizar a prática docente e de convidar os alunos para uma construção coletiva de conhecimento não era recomendado diante do padrão de comportamento que os próprios alunos demonstravam em sala de aula. Nesse ponto, podemos nos questionar: o que significa a expressão "descentralização pedagógica”? A que aspectos educacionais essa expressão se refere? Que aspectos da descentralização pedagógica pareciam incomodar tanto os professores que participaram da ação? 
De acordo com o dicionário online Dicio, o significado do termo "descentralização" é "afastar do centro", ou mesmo "transferir certos poderes e competências, característicos do poder central e concentrados num só lugar, para outros setores menores, periféricos ou locais" ${ }^{14}$. Nesse sentido, o ato de descentralizar não está necessariamente relacionado a uma diminuição de poder, mas a uma redistribuição que busque equilibrar o uso desse poder entre todas as partes.

Conforme percebemos nas palavras de uma participante do projeto, ainda que por vezes os docentes reconhecessem a necessidade de dar mais espaço aos discentes na construção do próprio conhecimento, o receio de perder a autoridade ou o controle da turma sempre era citado como uma dificuldade a ser considerada - experiência em contraposição às ideias de diálogo e de abertura comunicativa que a educomunicação propõe nos processos educacionais:

Professor com autoridade... pra eles [estudantes] só existe se chegar pra eles e gritar. Eles parecem que trazem de casa a cultura de só atenderem no grito. Se o professor chegar muito calmo, quiser conversar, eles dizem que o professor não tem autoridade ${ }^{15}$.

Percebemos na fala da professora Marie que a proposta de abrir mão de uma centralidade no ato pedagógico parece ser algo temeroso: para a docente, o ato de ensinar não pressupõe apenas boas intenções, mas acima de tudo condições (morais?) para realizá-lo. Nesse caso, o professor não deve apenas "ter" autoridade: ele deve também "parecer" alguém "poderoso", pois isso pressupõe poder de comando. Dessa forma, o docente deve transparecer essa autoridade em suas ações e em sua rotina pedagógica, já que - parafraseando a professora -, ele não pode "chegar muito calmo".

As palavras da professora Marie nos lembram que havia, entre os participantes do projeto de extensão, um forte discurso de apego ao planejamento pedagógico, como se apenas esse plano didático fosse capaz de auxiliar o professor em momentos de imprevisibilidade. Assim, o raciocínio da docente sugere que um bom professor não é aquele que simplesmente conversa demais com seus alunos, mas o profissional que está preparado para imprevistos e que, acima de tudo, não abre margem para que esses imprevistos aconteçam. Isso fez com que o planejamento pedagógico aparentemente não fosse apenas uma ferramenta de auxílio aos participantes da ação extensionista, mas também um mecanismo aprisionador da própria prática docente, tirando uma parcela da autonomia do educador e o deixando à margem de modelos que teoricamente o salvaria de dificuldades em suas aulas ${ }^{16}$.

Lago, Martins e Nonato ${ }^{17}$ afirmam que apesar de ter ganhado destaque no campo da educação nos últimos anos, o conceito de alteridade nem sempre é exercido de forma efetiva no contexto educacional. Do ponto de vista educomunicativo, percebe-se a falta de preocupação com o outro e suas necessidades, pois houve receio por parte dos participantes da ação em renunciar a uma "centralidade docente" em prol de uma descentralização da própria experiência didática, ou seja, em abrir mão de poder. Para os docentes, ter poder é essencial dentro de sala de aula e esse poder não pode ser diminuído
14. DESCENTRALIZAÇÃO. In: DICIO Dicionário Online de Português. Matosinhos: 7 Graus, [2020?]. Disponível em: https://www.dicio.com. br/descentralização/. Acesso em: 1 jul. 2020 .

15. Informação verbal, professora Marie, $3^{\circ}$ Encontro da Ação de Extensão, 28 ago. 2019

16. LUCKESI, Cipriano. Avaliação da aprendizagem escolar: estudos e proposições. 22a. ed. São Paulo: Cortez, 2011.

17. LAGO, Cláudia; MARTINS, Ferdinando; NONATO, Cláudia. A alteridade na Educomunicação. Comunicação \& Educação, São Paulo, v. 24, n. 2, p. 54-65, 2019. 
ou compartilhado, ainda que o aumento da participação dos estudantes nas atividades desenvolvidas na escola pareça pedagogicamente algo interessante.

Preocupar-se com as necessidades dos outros e tentar entender suas participações nos espaços é um desafio a que os professores são submetidos diariamente no ambiente escolar. O exercício de alteridade, ao identificar o "outro" aos alunos, parece muitas vezes caminhar em direção oposta à perda de autoridade dos docentes. A preocupação demonstrada por alguns participantes da ação com a participação dos alunos nas aulas choca-se com a ameaça dos alunos tomarem do professor uma parcela do poder que os caracterizam como docentes, comprovando que "reconhecer que há um outro não significa reconhecer este outro efetivamente" 18 .

Durante os encontros do projeto de extensão, era comum os participantes reclamarem do comportamento de seus alunos e de seus hábitos relacionados à forma como se comunicavam. Para os docentes, os alunos de suas turmas tinham uma tendência a falar de forma desorganizada e ansiosa, e esse era o principal motivo pelo qual os professores afirmavam não dar tanta voz às crianças nas atividades que eram realizadas em sala.

Durante um dos encontros, procurou-se compreender o que realmente incomodava os participantes da ação na forma como seus alunos se comunicavam. Na ocasião, os temas geradores que estavam sendo discutidos na formação pedagógica eram "poder" e "descentralização"; por isso, perguntei aos educadores se havia alguma forma de conciliar a maneira entusiasta com a qual seus alunos se comunicavam, e as atividades que eles propunham realizar em sala de aula. A resposta dada por uma das participantes foi emblemática:

Professora Presley: Eles querem ser ouvidos. Você vê a necessidade deles de serem ouvidos, né? Mas...

Prof. Marcus Henrique: Mas isso é ruim?

Professora Presley: Não, isso não é ruim. Mas por exemplo: eu começo a aula falando de plantas, e ai depois a aula tá numa coisa completamente diferente. Não é ruim, é até legal, mas aí a gente tem que também trazer pro foco: ó gente, vamos conversar sobre isso num outro momento ${ }^{19}$.

Mais uma vez, uma das participantes do projeto nos chamou a atenção para o fato de que os professores têm um planejamento pedagógico a ser seguido e os objetivos desse planejamento devem ser alcançados. Dessa forma, mesmo reconhecendo a importância dos alunos "serem ouvidos", a professora Presley enfatizou a necessidade que os docentes têm de trazer as discussões "pro foco" da aula, sem desperdiçar o tempo didático com divagações fora dos propósitos do conteúdo que estiver sendo abordado na aula. Aparentemente, o que os alunos têm a dizer nem sempre pode ser uma prioridade para a professora e pode ter menos importância que os conteúdos pedagógicos que devem ser ministrados.

18. Ibidem, p. 62.

19. Informação verbal, $4^{\circ}$ Encontro da Ação de Extensão, 4 set. 2019
Poderíamos considerar que a prática docente descrita pela professora Presley permaneceria centralizada, com o professor comandando de forma solitária as atividades realizadas em sala de aula por meio de pouco compartilhamento 
de experiências e de uma comunicação unilateral e focada na obtenção de resultados pedagógicos a curto prazo ${ }^{20}$.

Segundo Soares ${ }^{21}$, para que o processo de ensino seja realizado de forma proveitosa para alunos e professores, é necessário que a comunicação mantida nos diversos contextos educacionais seja feita de forma democrática e participativa de modo a se criar ecossistemas comunicativos. O trabalho compartilhado entre docentes e discentes, o respeito aos conhecimentos do "outro" e suas experiências de vida e a construção coletiva de conhecimento são pontos chave do pensamento educomunicativo e pressupõem um rompimento com a lógica centralizadora do ensino tradicional, que tende a concentrar na figura do professor todos os "poderes didáticos" relacionados ao processo de ensino-aprendizagem.

Todavia, apesar das intensas discussões realizadas nos últimos anos a respeito da criação de uma base curricular nacional, percebe-se que a escuta alteritária nem sempre está presente no contexto formal escolar, seja por falta de formação que possibilite aos docentes pensarem mais no outro (seus alunos) como produtores de conhecimento, seja por falta de uma política educacional clara que indique maneiras concretas de aperfeiçoar a qualidade da comunicação mantida entre docentes e discentes nos processos educacionais. Dessa forma, apesar dos documentos oficiais do ministério da educação fazerem alusão à necessidade de se "facilitar a gestão dos relacionamentos interpessoais no espaço escolar", esses documentos

não preveem espaços no currículo para que professores e alunos disponham de condições de tempo para o indispensável acesso a uma formação específica que lhes garanta conhecimentos suficientes para cumprir o que a eles está sendo proposto $^{22}$.

Percebe-se que a dificuldade dos profissionais da educação em criar ecossistemas comunicativos em suas aulas é consequência direta da falta de uma formação continuada que os capacite a descentralizarem suas próprias ações pedagógicas. Dessa forma, os professores tornam-se vítimas do próprio sistema educacional no qual estão inseridos, e o receio que os participantes da ação de extensão manifestaram em dar voz a seus alunos talvez seja um sintoma nítido desse déficit formativo.

É importante enfatizar novamente que a preocupação dos participantes do projeto de extensão em conduzir suas aulas de forma centralizada e o receio que demonstraram com a ideia de perder autoridade perante os alunos caso permitissem a participação discente de forma mais ampla nem sempre era acompanhada de uma necessária desvalorização dos alunos; alguns professores ressaltaram a necessidade de dar voz e espaço para os estudantes manifestarem suas visões sobre os conteúdos trabalhados nas aulas. Para uma das participantes, é preciso estabelecer uma separação entre os conceitos de "autoridade" e "autoritarismo", e essa diferenciação é crucial para o sucesso da ação docente:

A diferença é que você é que conduz aquela aula. Vocêe precisa conduzir, você precisa mediar, mas você também não pode querer mediar só do seu jeito. Você tem que deixar que
20. SAVIANI, Dermeval. Educação em diálogo. Campinas: Autores Associados, 2011.

21. SOARES, Ismar de Oliveira. A educomunicação possível: uma análise da proposta curricular do MEC para o Ensino Básico. Comunicação \& Educação, São Paulo, v. 21, n. 1, p. 13-25, 2016.

22. SOARES, 2016, p. 17. 
comunicação \& educação • Ano XXV • número 2 • jul/dez 2020

eles [alunos] participem, que eles se incluam, que eles tenham o olhar deles, que sejam respeitados e trazer pra discussão. Então eu acho que assim: dar a eles essa capacidade de refletir, de reelaborar, de pensar, e a gente [os professores] tem esse poder de conduzir isso, porque somos nós os professores ${ }^{23 !}$

A declaração dada pela professora Angel durante o $4^{\circ}$ encontro da ação de extensão se deu no momento de discussão coletiva, a fase de prova na sequência Fedathi, quando os participantes da formação pedagógica estavam compartilhando suas reflexões a respeito dos temas geradores que estavam sendo debatidos. Nesse momento, diversos posicionamentos foram manifestados por parte dos docentes, e suas reflexões sobre os conceitos de "descentralização pedagógica" e "poder" se manifestaram, às vezes, de maneira contraditória, o que enriqueceu bastante as discussões realizadas.

Para a professora Angel, a participação dos alunos é algo importante e essencial para a prática pedagógica. Dessa forma, a docente enfatiza a necessidade de conseguir que os alunos "participem, se incluam e tenham o olhar deles" sobre os conteúdos ministrados nas aulas. Todavia, o que parece ser um discurso liberal da professora ganha tons centralizadores quando a própria também enfatiza o fato de essa participação ser conduzida pelos professores, porque apenas os docentes "têm esse poder de conduzir isso". Nesse caso, tem-se aqui uma fala alteritária e um discurso pedagógico descentralizado com leves tons de centralização pedagógica no que tange ao exercício do poder no espaço da sala de aula, confirmando o fato dos participantes da ação de extensão cultivarem a ideia de que "a disciplina de uma turma está diretamente ligada ao estilo da prática docente, ou seja: à autoridade profissional, moral e técnica do professor" ${ }^{24}$.

\section{CONSIDERAÇÕES FINAIS}

O projeto de extensão realizado em uma escola municipal de Fortaleza revelou aspectos interessantes da prática docente dos participantes: a maioria dos professores que participou da ação revelou estar diretamente envolvida em uma concepção centralizadora do ato de ensinar, assumindo completamente a frente das atividades realizadas em suas aulas e dando aos alunos espaço limitado de interação frente aos conteúdos ministrados.

O discurso de desconforto dos docentes em relação ao conceito de "descentralização pedagógica” e às ideias como compartilhamento de experiências e construção coletiva do conhecimento, que são princípios educomunicativos, não tornam os participantes do projeto "vilões"; em vez disso, eles devem ser analisados como personagens cuja atuação profissional é reflexo da influência recebida das políticas educacionais brasileiras que, por sua vez, enfatizam a obtenção de resultados pedagógicos a curto prazo, estimulando ações docentes focadas numa obediência irrestrita ao planejamento pedagógico. 
Durante os dois meses de estadia na escola visitada, os participantes foram incentivados a tomarem consciência da importância de se construir uma aprendizagem coletivizada e descentralizada a partir dos debates realizados sobre os conceitos educomunicativos abordados nos encontros. Todavia, o receio demonstrado pelos participantes a respeito da possibilidade de perda da autoridade em suas aulas revelou-se maior que o imaginado e, já no fim da ação extensionista, muitos professores ainda pareciam recusar a possibilidade de abrir mão de uma parcela (ainda que pequena) de seu "poder" em sala de aula, mesmo que em prol de um enriquecimento da eloquência de seus alunos.

A ênfase dada pelos docentes ao exercício de autoridade em sala de aula ainda é um resquício da valorização dada pelos professores à importância da imagem social que defendem ter perante os alunos. Essa centralidade da imagem do professor como único condutor das atividades realizadas no contexto escolar requer uma carga de poder que precisa ser utilizada para sustentar seu cotidiano profissional. Nesse contexto, propor uma divisão desse poder entre docentes e discentes pareceu soar como algo perigoso aos participantes de nosso projeto de extensão, uma vez que poderia desequilibrar toda essa estrutura centralizadora que embasava grande parte das experiências profissionais dos participantes.

As discussões realizadas em cada encontro foram conduzidas com a preocupação de tomar a realidade pedagógica dos próprios professores como ponto de partida dos debates. Nesse sentido, o uso da sequência Fedathi e de seus princípios descentralizadores como metodologia do projeto revelou-se uma escolha benéfica à formação pedagógica, uma vez que permitiu aos participantes compartilharem suas reflexões sobre as dificuldades que encontram em suas aulas.

Além disso, uso de temas geradores para embasar as reflexões dos participantes enriqueceu os debates realizados nos encontros da formação, uma vez que permitiu o acesso direto à interpretação dada pelos docentes a respeito dos conceitos trabalhados em cada encontro.

De forma geral, conclui-se que as práticas pedagógicas dos professores participantes da ação extensionista misturavam aspectos pedagógicos centralizadores a "choques" de consciência dos docentes, que reconheciam a importância da participação de seus alunos nas aulas. Todavia, ainda que tivessem um discurso de valorização dessa participação, os participantes do projeto de extensão nem sempre pareciam ter uma ação realmente alteritária; ao invés disso, sua prática pedagógica respaldava-se em ações por vezes autoritárias, deixando a preocupação com o dizer do "outro" (os alunos) em segundo plano, em detrimento aos conteúdos ministrados em sala de aula.

Diante do que foi observado na ação de extensão, fica clara a necessidade cada vez mais urgente de políticas educacionais que apresentem maneiras concretas de aperfeiçoamento da comunicação mantida entre docentes e discentes dentro do espaço escolar. A melhoria na qualidade da comunicação mantida entre professores e alunos passa quase que necessariamente por uma abertura docente à visão dos estudantes como sujeitos construtores (e também 
produtores) de conhecimentos, e não apenas figuras passivas de um processo unilateral de transmissão de conteúdo. Apenas desse modo o receio docente à perda de autoridade ou de controle de suas turmas poderá ser substituído por uma conscientização de que os processos educacionais são efetivamente fenômenos de construção coletiva e não situações estanques e solitárias de abordagem de conceitos.

Finalmente, gostaríamos de agradecer à escola participante de nossa ação de extensão pela extrema gentileza com que fomos recebidos por gestores e professores participantes das atividades do projeto. Também dedicamos especiais agradecimentos às colaboradoras voluntárias do projeto, as pesquisadoras Sara Rebeca Aguiar de Carvalho e Cristina Mandau Ocuni Ca, por todo o apoio que nos prestaram no andamento da ação extensionista, inclusive participando das discussões promovidas junto aos participantes do projeto, assim como ao Laboratório de Pesquisas Multimeios por todo o apoio oferecido na realização deste trabalho.

\section{REFERÊNCIAS BIBLIOGRÁFICAS}

BORGES NETO, Hermínio (org). Sequência Fedathi: fundamentos. Curitiba: CRV, 2018.

BORGES NETO, Hermínio et al. (org.). Sequência Fedathi: uma proposta pedagógica para o ensino de ciências e matemática. Fortaleza: Edições UFC, 2013.

DESCENTRALIZAÇÃO. In: DICIO Dicionário Online de Português. Matosinhos: 7 Graus, [2020?]. Disponível em: https://www.dicio.com.br/ descentralização/. Acesso em: 1 jul. 2020.

FERREIRA, Flávia de Carvalho. Contraexemplo. In: BORGES NETO, Hermínio (org). Sequência Fedathi: fundamentos. Curitiba: CRV, 2018. p. 49-54.

FREIRE, Paulo. Pedagogia da autonomia. Rio de Janeiro: Paz e Terra, 2014.

FREIRE, Paulo. Pedagogia do oprimido. Rio de Janeiro: Paz e Terra, 2014.

KAPLÚN, Mario. Uma pedagogia da comunicação. In: APARICI, Roberto (org.). Educomunicação: para além do 2.0. São Paulo: Paulinas, 2014. p. 59-80.

LAGO, Cláudia; MARTINS, Ferdinando; NONATO, Cláudia. A alteridade na Educomunicação. Comunicação \& Educação, São Paulo, v. 24, n. 2, p. 54-65, 2019.

LIBÂNEO, José Carlos. Didática. 2a. ed. São Paulo: Cortez, 2013.

LUCKESI, Cipriano. Avaliação da aprendizagem escolar: estudos e proposições. 22a. ed. São Paulo: Cortez, 2011.

MENEZES, Daniel Brandão. Prova. In: BORGES NETO, Hermínio (org). Sequência Fedathi: fundamentos. Curitiba: CRV, 2018. p. 99-106. 
SANTANA, Ana Carmen de Souza. Mão no bolso: postura, metodologia ou pedagogia? In: BORGES NETO, Hermínio (org). Sequência Fedathi: fundamentos. Curitiba: CRV, 2018. p. 15-22.

SAVIANI, Dermeval. Educação em diálogo. Campinas: Autores Associados, 2011. SOARES, Ismar de Oliveira Educomunicação: o conceito, o profissional, a aplicação. São Paulo: Paulinas, 2011.

SOARES, Ismar de Oliveira. A educomunicação possível: uma análise da proposta curricular do MEC para o Ensino Básico. Comunicação \& Educação, São Paulo, v. 21, n. 1, p. 13-25, 2016.

SOUZA, Maria José Araújo. Sequência Fedathi: apresentação e caracterização. In: BORGES NETO, Hermínio et al. (org.). Sequência Fedathi: uma proposta pedagógica para o ensino de ciências e matemática. Fortaleza: Edições UFC, 2013. p. 15-48. 